\title{
Entre os gramados e os trilhos: a história do Paulista Futebol Clube de Jundiaí
}

\author{
[ Between fields and rails: the history of Jundiai's Paulista Futebol Clube
}

\section{Guilherme Grandi ${ }^{x}$}

\section{Marcelo Roubicek ${ }^{2}$}

RESUMO - O presente artigo investiga a relação entre o Paulista Futebol Clube de Jundiaí e a Companhia Paulista de Estradas de Ferro nas duas primeiras décadas do século XX. A partir do cruzamento de fontes documentais do Clube com o Banco de Dados Ferrovia, Cidade e Trabalhadores, a conquista do Oeste (I850-I920), revela-se o perfil dos ferroviários participantes da agremiação futebolística, trazendo à tona a dimensão paternalista das relações entre a equipe de futebol e a ferrovia. • PALAVRAS-CHAVE - Futebol; ferrovia; Paulista F.C. A ABSTRACT - This study investigates the relationship between Jundiaí's Paulista Futebol Clube and Companhia Paulista de Estradas de Ferro during the first two decades of the $2 \mathrm{O}^{\text {th }}$ century. Through the crossing of information from the club's sources and the database Ferrovia, Cidade e Trabalhadores, a conquista do Oeste (I850-I920), the study shows the profile of the railway workers that participated in the football club, revealing the paternalist dimension of the relations between the football team and the railway company. - KEYWORDS · Football; railway; Paulista F.C.

Recebido em II de setembro de 2020

Aprovado em I6 de julho de $202 \mathrm{I}$

GRANDI, Guilherme; ROUBICEK, Marcelo. Entre os gramados e os trilhos: a história do Paulista Futebol Clube de Jundiaí. Revista do Instituto de Estudos Brasileiros, Brasil, n. 79, p. I04-I23, ago. 202I.

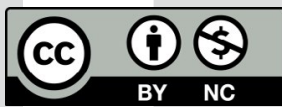

DOI: https://doi.org/Io.II606/issn.23I6-90IX.vIi79pI04-I23

I Universidade de São Paulo (USP, São Paulo, SP, Brasil).

2 Universidade de São Paulo (USP, São Paulo, SP, Brasil). 
O surgimento de equipes de futebol no Brasil durante a primeira metade do século XX é comumente associado, pela historiografia especializada, ao avanço das companhias de estradas de ferro pelo território nacional3. Buchmann (2004) levanta dezenas de equipes originalmente vinculadas aos trabalhadores ferroviários do país, e o estado de São Paulo, em particular, se destaca a esse respeito, haja vista que ao menos 40 equipes de futebol foram organizadas por essa categoria profissional em todo $o$ estado. Entre tantos clubes fundados por ferroviários e empresas de estradas de ferro, muitos se mantêm ainda ativos, tendo alcançado relativo sucesso esportivo ao longo das décadas. O Nacional Atlético Clube (antigo São Paulo Railway Athletic Club), o Ituano Futebol Clube, o Esporte Clube Noroeste (de Bauru) e a Associação Ferroviária de Esportes (de Araraquara), são alguns exemplos de clubes do interior paulista que foram fundados por iniciativa de empresas ferroviárias e seus funcionários.

Costa (I976, p. I60) associa a instalação das estradas de ferro com os primórdios do trabalho assalariado no Brasil e, portanto, com uma nova relação econômica, pautada pela lógica capitalista, que foi inserida em um sistema produtivo tipicamente escravista no decorrer da segunda metade do século XIX. Nesse sentido, o ferroviário pode ser entendido como o que a autora chama de "proletariado precoce e embrionário".

Lanna (20I6, p. 532), por sua vez, observa que a divisão do trabalho era uma das características mais marcantes da estrutura laboral existente no interior das companhias ferroviárias. A subdivisão de tarefas e cargos em diversas seções de trabalho favorecia a hierarquização dos trabalhadores e, ao mesmo tempo, possibilitava a eles construir longas carreiras numa mesma empresa. Em outras palavras, a divisão da estrutura organizacional das empresas ferroviárias em inúmeros departamentos incentivava o operário a iniciar de baixo, como aprendiz, por exemplo, induzindo-o a buscar a progressão na carreira ao longo dos anos. Cabe apontarmos ainda para um aspecto central das relações de trabalho do setor ferroviário: a recorrente fidelidade dos operários à empresa, uma decorrência

3 Sobre a vinculação dos clubes de futebol com empresas ferroviárias em São Paulo, consultar, dentre outros trabalhos citados ao longo deste estudo, o artigo de Almeida, Gutierrez e Ferreira (20I0). 
direta do paternalismo ${ }^{4}$ existente nesse setor em São Paulo. Dado que muitos ferroviários passavam a vida inteira na mesma companhia, criava-se uma cultura de identificação desses trabalhadores com a "filosofia" da empresa, que inspirava respeito e admiração por ela, e com o serviço ferroviário, logo, com a rotina de trabalho em uma diversidade de funções que se complementavam entre si.

A carreira de ferroviário era transmitida por laços de família e, portanto, havia um caráter hereditário que se difundia por gerações. Era comum a profissão ser passada de pai para filho, com o herdeiro repetindo o ciclo profissional do seu progenitor ao iniciar na profissão em cargos inferiores, buscando perseguir paulatinamente postos mais elevados na estrutura produtiva e organizacional da ferrovia. Além disso, as empresas ferroviárias costumavam abrir vagas e espaços de atuação exclusivos para os filhos de seus funcionários, a exemplo dos cursos de formação profissional oferecidos pelas próprias companhias em suas oficinas de construção, reparo e manutenção do material ferroviário (SEGNINI, I982; LANNA, 20I6; INOUE; GRANDI, 202I).

Tudo isso contribuía para a emergência da "família ferroviária", configuração segundo a qual os operários se organizavam em torno da identidade comum ao trabalho e do sentimento de pertencimento a um grupo social específico, que, inseridos em uma estrutura produtiva e um ambiente profissional marcados por uma cultura paternalista de gestão empresarial, seguiam fiéis ao trabalho disciplinado ao se sentirem honrados pelos cargos ocupados e funções exercidas. As diretorias dessas estradas incentivavam, por meio de práticas paternalistas, esse tipo de organização e de sentimento entre os funcionários ao agir como o pater familis. O próprio lema "Trabalho, Família e Companhia Paulista" explicita tal relação (LANNA, 20I6, p. 526).

Para Segnini (I982, p. 80), a relação de trabalho no setor ferroviário se caracteriza, dentre outras coisas, pela introjeção da "moral patronal", ou seja, pela inserção dos valores da corporação nas relações cotidianas vividas pelos trabalhadores. Quando se considera a hierarquização presente nas empresas e se retoma a ideia de uma estrutura dividida em vários níveis, é possível inferir que a moral patronal começava dos níveis hierárquicos mais altos e ia descendo, se disseminando através de microrrelações de poder estabelecidas no interior da empresa. Esse caminho era percorrido de forma pessoal, resultando na transmissão e reprodução dos valores empresariais nos ambientes sociais e privados dos ferroviários.

Diante do exposto nesta breve introdução, a organização dos operários para a prática esportiva também era um dos espaços sociais produzidos e, portanto, forjados pelas relações paternalistas de produção que marcaram a gestão empresarial das companhias ferroviárias paulistas. O presente artigo busca investigar como tal

4 Via de regra, o paternalismo busca assegurar a dominação do capital sobre o trabalho, uma vez que empresas organizadas sob tal modelo de gestão procuram atender às necessidades dos seus funcionários em troca de um comportamento que denote gratidão e lealdade à empresa. Nesse sentido, a aceitação do domínio se dá por meio da disciplina e subordinação irrestrita dos trabalhadores à gerência empresarial, além do esforço constante dos subordinados em corresponder às expectativas da direção da empresa (TEIXEIRA, I984). Para um aprofundamento sobre a questão do paternalismo na Companhia Paulista de Estradas de Ferro entre as décadas de I920 e I940, ver: Inoue e Grandi (202I). 
configuração se manifestava nos clubes de futebol e, em especial, como era refletida pelos próprios membros das agremiações futebolísticas. Nosso estudo, contudo, examina a história de um clube específico que se originou da Companhia Paulista de Estradas de Ferro (doravante Companhia Paulista). Trata-se do Paulista Futebol Clube de Jundiaí (doravante Paulista F.C.).

\section{METOdOLOGIA, OBJETIVO E ESTRUTURA DO ARTIGO}

Antes de iniciar a análise, é necessário explicitarmos que o presente estudo se baseia no exame de documentos selecionados que compõem o acervo do Centro de Memória de Jundiaí (CMJ), vinculado ao Museu Histórico e Cultural de Jundiaí, da Unidade de Gestão de Cultura do Município. Nesse acervo, foi possível consultar diversos documentos referentes a vários períodos da história do Paulista F.C., incluindo jornais, fotos, livros de ofícios, atas de reunião, entre outros. Para a elaboração deste artigo, o principal documento consultado foi o Livro de Ofícios do Paulista Foot Ball Club, que compreende o período entre janeiro de I9I5 e fevereiro de I9I9 e constitui, junto com o acervo fotográfico e alguns outros documentos (tais como a ata de fundação e trechos de jornais), o registro mais antigo das atividades do clube, cuja fundação remonta ao ano de I909.

A principal técnica de pesquisa utilizada neste estudo foi o cruzamento de dados e informações encontrados sobre o clube no material empírico por nós selecionado no CMJ e no Banco de Dados Ferrovia, Cidade e Trabalhadores, a conquista do Oeste (I850-I920), organizado por Lanna (2000). A técnica do cruzamento de fontes primárias nos permitiu identificar os membros das primeiras gerações do Paulista F.C. que foram contratados pela Companhia Paulista no período compreendido pelo banco de dados, sendo este o objetivo principal do presente artigo. $O$ resultado completo desse cruzamento pode ser conferido na Figura I. 


\begin{tabular}{|c|c|c|c|c|c|c|c|c|c|c|}
\hline Nome & Nacionalidade & Ano de Admissão & Idade na Admissão & Anos de Empresa & $1^{\circ}$ Cargo & Último cargo & $1^{\circ}$ salário & Último Salário & Motivo de saída & Posição no Paulista \\
\hline Adào Gray & Escocts & 1888 & 20 & 43 & Ajustador & Chefe de Oficinas & $2078000 /$ mess & $18005000 /$ més & Aposentadoria & Sócio \\
\hline Melchior Almeida & Portugués & 1891 & 17 & 41 & Aprendiz de Ajustador & & $3 \$ 500 /$ dia & & Demissão & $1^{\circ}$ Tesourciro \\
\hline Accacio Simöes & - & 1891 & - & 32 & Ajustador & - & $5 \$ 500 /$ dia & $15800 /$ hora & Aposentadoria & Sócio \\
\hline Gustavo Storch & - & 1892 & - & 36 & Chefe de Oficinas & Chefe de Oficinas & $320 \$ 000 /$ mess & $320 \$ 000 / \mathrm{m} \hat{\mathrm{s}} \mathrm{s}$ & Aposentadoria & Sócio Honorário \\
\hline Francisco Santos Paes & Brasileiro & 1894 & 16 & 37 & Telegrafista & $1^{\circ}$ Escriturário & $1458000 / \mathrm{més}$ & $600 \$ 000 / \mathrm{mets}$ & Aposentadoria & Sócio \\
\hline Carlos Jorge Marques & - & 1894 & - & 30 & Chefe & Escriturário & $1805000 /$ mess & $370 \$ 000 / \mathrm{més}$ & Aposentadoria & Sócio \\
\hline José Mantilla & - & 1895 & - & 28 & Rebitador & Caldeireiro & $78000 /$ dia & $25000 /$ hora & Aposentadoria & Tesourciro \\
\hline Olynpio Arruda & Brasileiro & 1896 & 14 & 33 & Praticante Escriturário & - & $505000 / \mathrm{mês}$ & $14005000 / \mathrm{mes}$ & Aposentadoria & Sócio \\
\hline Tiburcio Siqueira & Brasileiro & 1896 & - & 32 & Escriturário & Ajudante de Almoxarifado & $150 \$ 000 /$ mes & $15008000 /$ mâs & Aposentadoria & Presidente \\
\hline Alfredo Ehrahrdt & - & 1896 & - & 28 & Fundidor & - & $85000 /$ dia & - & Aposentadoria & Sócio \\
\hline José Faggiani & - & 1897 & - & 31 & Aprendiz & Chefe da Tipografia & $4 \$ 500 /$ dia & $900 \$ 000 /$ mês & Aposentadoria & $2^{\circ}$ Tesoureiro \\
\hline Nicomedes Correa & Brasileiro & 1900 & 13 & 50 & Aprendiz de Fundidor & Inspetor de Carros e Vagōes & $\$ 500 /$ dia & - & Apos. especial & Comissāo de Sindicância / \\
\hline Arthur Marcianno & Brasileiro & 1900 & 12 & 39 & Praticante Telegrafista & Chefe de Seçăo & $255000 /$ mês & $900 \$ 000 /$ mês & Aposentadoria & Sócio \\
\hline Frederico Fuller & Brasileiro & 1901 & 15 & 48 & Aprendiz de Ajustador & Contra Mestre & $\$ 500 /$ dia & $\mathrm{Cr} \$ 1500 / \mathrm{m}$ ts & Aposentadoria & Sócio / Comissão de Sindicância / Dir. Esportivo \\
\hline Americo Bertolini & Brasileiro & 1903 & 13 & 46 & Aprendiz de Fundidor & Chefe de Turma & $\$ 500 /$ dia & $\mathrm{Cr} \$ 1750 / \mathrm{m} \hat{\mathrm{s}}$ & Aposentadoria & Vice Diretor Esportivo / Conissāo de Futebol \\
\hline Carlos Cordts & Brasileiro & 1904 & 17 & 35 & Mensageriro & Chefe da Sessăo de Arquivo & $100 \$ 000 /$ mes & & Aposentadoria & $1^{\circ}$ Sccretirio \\
\hline Joaquim C. Santos & Brasileiro & 1904 & 16 & 34 & Praticante Telegrafista & Chefe de Seçăo & - & $900 \$ 000 / \mathrm{més}$ & Aposentadoria & Sócio \\
\hline Joaquim E. Oliveira & Brasileiro & 1906 & 17 & 43 & Mensagciro & Auxiliar Administrativo & $755000 /$ mês & $\mathrm{Cr} \$ 1500 /$ mès & Apos. especial & Tesourciro \\
\hline Amadeu Giannazzi & Brasileiro & 1906 & 15 & 43 & Trabalhador & Ajudante de Apontador & $35000 /$ dia & 15500 / hora & Aposentadoria & Sócio \\
\hline Benedicto Santos & Brasileiro & 1906 & 17 & 27 & Furador & Ajustador & $3 \$ 500 /$ dia & 15600 / hora & Falecimento & Sócio \\
\hline Sidney John Normanton & Brasileiro & 1907 & 15 & 42 & Aprendiz de Ajustador & Mestre & $1 \$ 000 /$ dia & $\mathrm{Cr} 52500 /$ més & Aposentadoria & Sócio \\
\hline Francisco Soares & Brasileiro & 1908 & 13 & 41 & Aprendiz de Ajustador & Ajustador & $1 \$ 000 / \mathrm{dia}$ & Cr\$ $6,25 /$ hora & Aposentadoria & Sócio \\
\hline Carlos Elg & Brasileiro & 1908 & 15 & 41 & Aprendiz de Tomeiro & Frezador & $15000 /$ dia & $\operatorname{Crs} 6,25 /$ hora & Aposentadoria & Sócio / Capitáo \\
\hline Antonio Marques Mora & Espanbol & 1908 & 15 & 41 & Praticante Escriturário & Auxiliar Administrativo & $205000 /$ més & $21000000 /$ més & Aposentadoria & Sócio \\
\hline José Sarnento Netto & Brasileiro & 1909 & 15 & 40 & Praticante Telegrafista & Assistente de Contador & - & $200005000 / \mathrm{mss}^{\hat{k} \mathrm{~s}}$ & Apos. especial & Sócio \\
\hline Alvaro Nazareth & Brasileiro & 1910 & 13 & 39 & Aprendiz de Ajustador & Mestre & $1 \$ 800 /$ dia & $\mathrm{Cr} \$ 2416 / \mathrm{mets}$ & Aposentadoria & Sócio \\
\hline Jayme Chittenden & Inglès & 1910 & 14 & 39 & Aprendiz de Ajustador & Auxiliar de Inspetor & $\$ 500 /$ dia & $1800 \$ 000 / \mathrm{mcs}$ & Aposentadoria & Sócio / Capitão \\
\hline lgnacio Duarte & Brasileiro & 1910 & 16 & 39 & Aprendiz de Fundidor & Fundidor & $\$ 500 /$ dia & $6 \$ 400 /$ dia & Aposentadoria & Sócio \\
\hline Eugenio Zchel & Brasileiro & 1911 & 15 & 38 & Aprendiz de Tomeiro & $1^{\circ}$ Oficial & $\$ 500 / \mathrm{dia}$ & $25500 /$ hora & Aposentadoria & Sócio \\
\hline José Maria Corrèa Lemos & Brasileiro & 1912 & 19 & 37 & Praticante Escriturário & $1^{\circ}$ Escriturário & $50 \$ 000 /$ més & $\mathrm{Cr} \$ 1300 / \mathrm{mets}$ & Aposentadoria & Sócio \\
\hline Henrique Beisiegel & Brasileiro & 1912 & 15 & 37 & Aprendiz de Ajustador & Oficial 1 & $\$ 500 /$ dia & $\mathrm{Cr} \$ 7,50 /$ hora & Aposentadoria & Sócio \\
\hline Gaspar G. da Silva & Brasileiro & 1912 & 18 & 37 & Praticante Escriturário & Chefe de Seção & $405000 /$ més & - & Aposentadoria & Sócio \\
\hline Waldemar de Godoy & Brasileiro & 1912 & 16 & 33 & Trabalhador & Torneiro Mecânico & $3 \$ 500 /$ dia & $25000 /$ hora & Falecimento & Sócio \\
\hline Emilio Tordello & Brasileiro & 1913 & 20 & 36 & Continuo & Escriturário 4 & $120 \$ 000 / \mathrm{mes}$ & $450 \$ 000 /$ mês & Aposentadoria & Sócio \\
\hline Auggusto Maia & Brasileiro & 1913 & 15 & 36 & Aprendiz de Carpinteiro & Modelador & $\$ 500 /$ dia & $\$ 900 /$ hora & Aposentadoria & Sócio \\
\hline Antonio Grassi & Italiano & 1913 & 17 & 33 & Mallhador & Apontador & $45000 /$ dia & $\mathrm{Cr} 5950 / \mathrm{més}$ & Aposentadoria & Sócio \\
\hline Benedicto Pompeu & Brasileiro & 1913 & 19 & 15 & Marteleiro & Malhador & - & & Exoneraçĩo & Sócio \\
\hline Anthero dos Santos & Brasileiro & 1914 & 12 & 36 & Aprendiz de Ajustador & Ajustador & $\$ 500 /$ dia & Cr\$ $6,25 /$ hora & Apos. especial & Sócio \\
\hline Rosario Bruno & Italiano & 1914 & 23 & 22 & Funileiro & Caldeireiro & $5 \$ 000 /$ dia & $2 \$ 200 /$ hora & Aposentadoria & Sócio \\
\hline Wenceslau Znyslowski & - & 1915 & - & 12 & Foguciro & Fogueiro & $75000 / \mathrm{dia}$ & $15200 /$ hora & Falccimnto & Sócio \\
\hline Joầ Normanton Jr & Brasileiro & 1916 & 14 & 33 & Praticante Escriturário & Assistente & $305000 /$ mês & $\mathrm{Cr} \mathbf{S} 3500 /$ mês & Aposentadoria & Sócio Honorário \\
\hline Manoel Penna & Brasileiro & 1917 & 20 & 32 & Trabalhador & Ajustador & $3 \$ 500 /$ dia & $1 \$ 500 /$ hora & Aposentadoria & Sócio \\
\hline Carlos Canpos & Brasileiro & 1917 & 20 & 32 & Tipógrafo & Tráfego & $905000 /$ mês & - & Apos. especial & Sócio \\
\hline Attilio Bragantini & Brasileiro & 1918 & 22 & 31 & Ajudante de Ajustador & Marcenciro & $4 \$ 500 / \mathrm{dia}$ & $15600 /$ hora & Aposentadoria & Sócio / Capt. / Arrbitro / Comisså̃o de Futcbol \\
\hline
\end{tabular}

Figura I - Integrantes das primeiras gerações do Paulista F.C. contratados pela Cia. Paulista, I888-I9I8

Mais do que a coincidência de nomes que constam nas duas fontes, nos foi possível identificar as funções assumidas pelos indivíduos nas duas organizações - o clube e a ferrovia -, reconhecendo características e traços de cada uma delas. Além disso, foram transcritos alguns trechos desses documentos que complementam e enriquecem a ilustração do quadro histórico que representa a relação entre a agremiação futebolística e a empresa ferroviária. Assim, optamos por subdividir nosso estudo em mais duas seções, além das considerações finais. A seção a seguir trata das origens do Paulista F.C., ao passo que a seção subsequente versa sobre a relação entre o Clube e a Companhia Paulista.

\section{TRABALHO FERROVIÁRIO, PRÁTICA ESPORTIVA E HEREDITARIEDADE}

A primeira tentativa de criação de um time de futebol ligado aos ferroviários da Companhia Paulista alocados no município de Jundiaí, fundamentalmente nas oficinas de construção, reparos e manutenção do material ferroviário, se deu em I9O3 por meio do Jundiahy Foot Ball Club (LANNA, 20I6, p. 540). A agremiação foi fundada pelos trabalhadores da Companhia, e a primeira partida foi disputada em 24 de junho de 1903 contra a Associação Atlética União da Lapa, equipe oriunda do bairro operário da Lapa, da cidade de São Paulo, onde a presença de ferroviários da companhia inglesa São Paulo Railway também era expressiva. Lucato (2002, p. I9-27) nota que o jogo foi realizado em um campo no bairro da Barreira, próximo à sede da Companhia Paulista 
em Jundiaí, e que os atletas usaram como vestiário um vagão de trem situado nas proximidades do campo onde se realizou a partida. A equipe da Lapa venceu por um a zero. A escalação do Jundiahy para esse jogo foi a seguinte: John Normanton; A. Henworthy e T. Scott; G. Hanikel, Curadi e Pacheco; Ribeiro, Rogek, J. Henworthy, Frederico Fuller e Leite; na reserva, J. Simões e A. Simões (LUCATO, 2002, p. 2I).

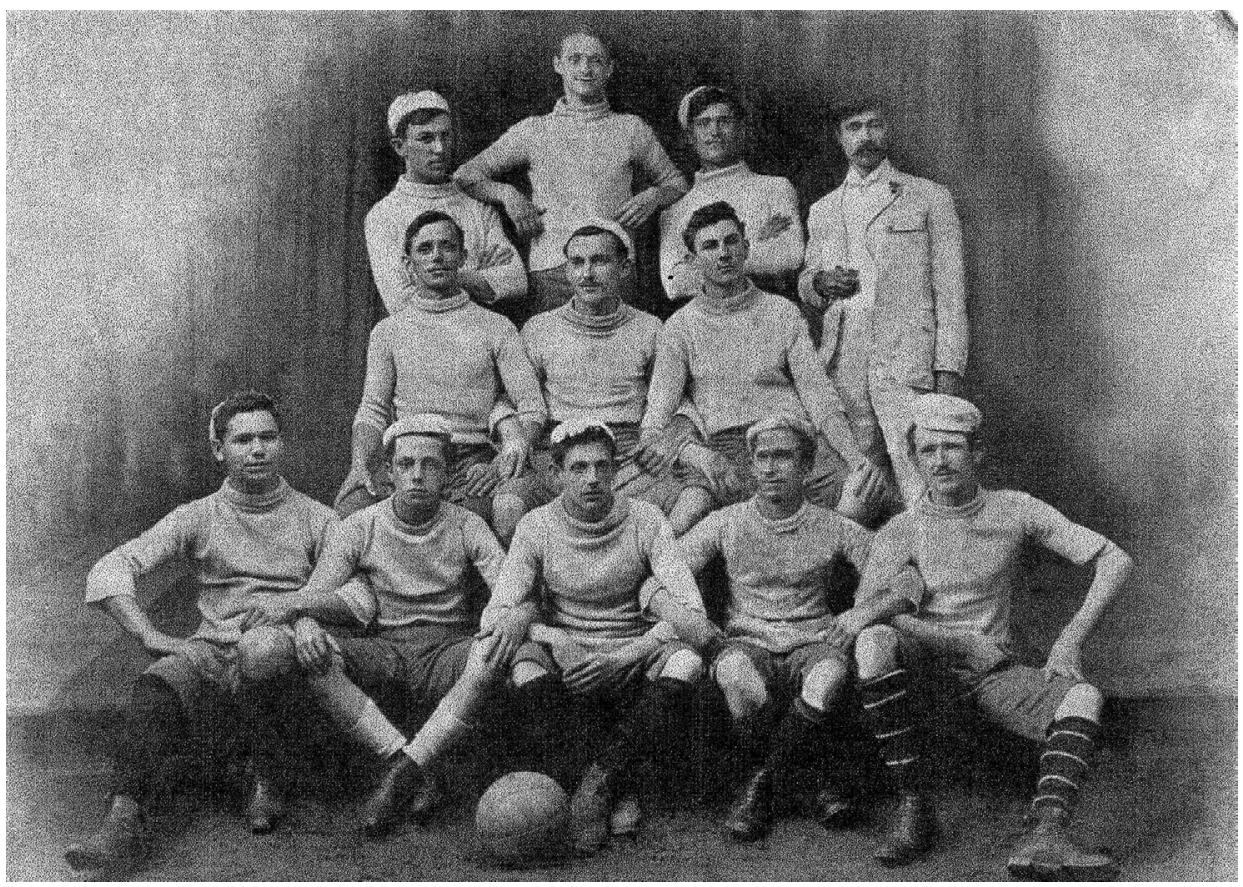

Figura 2 - Equipe do Jundiahy Foot Ball Clube. Registro feito entre I903 e I908. Foto cedida por Márcio José Dias

Uma curiosidade a respeito desse confronto foi revelada pelo jornal $O$ Estado de S. Paulo do dia 23 de junho de I903, no qual o Jundiahy foi apresentado como o time do Grêmio Recreativo dos Empregados da Companhia Paulista. O Grêmio Recreativo era uma organização formada por trabalhadores da ferrovia para a realização de eventos dedicados ao lazer e entretenimento, como bailes dançantes e sessões de cinema. Estaria o Jundiahy F.C., de fato, ligado diretamente a essa agremiação? Ao que tudo indica, sim. No entanto, é importante pontuarmos que havia à época uma evidente indefinição acerca do que era uma organização fundada especificamente para a prática do futebol, em relação a outras voltadas para formas diversas de lazer e entretenimento praticadas pelos empregados da Companhia Paulista.

$\mathrm{O}$ fato, no entanto, é que o Jundiahy Foot Ball Club teve vida efêmera, sendo extinto em 1908 em decorrência da morte de um dos seus fundadores (LANNA, 20I6, p. 540). Todavia, não tardou para que houvesse uma nova tentativa de organizar um clube de futebol ferroviário em Jundiaí. Em I7 de maio de I909, o Paulista Foot Ball Club foi fundado como resultado da reunião realizada ao pé do 
trem $\mathrm{n}^{\circ}$ 34, no pátio de manobras da Companhia Paulista. Segue a transcrição do seu documento de fundação:

\author{
Associação: - 'Paulista Foot Ball Club' \\ Tendo sido por indicação do sócio $I^{\circ}$ secretário da assembleia, proposto o uniforme \\ haver com monogramma sobre o lado esquerdo em todas as camisas, ( $\mathrm{I}^{\circ}$ e $2^{\circ}$ teams) $\mathrm{o}$ \\ sr. presidente da assembleia nomeou-se em comissão para estudar a indicação. \\ Tendo-se discutido as propostas apresentadas, procedeu-se à eleição da directoria que \\ dirigirá os destinos da associação durante o corrente anno, dando a sua apuração o \\ seguinte resultado: \\ Presidente: - John Lewis Jones \\ Vice ": - Williams Knox \\ I secretário: - Carlos Bloch \\ 2 ": - Luis Carvalho \\ $\mathrm{I}^{\circ}$ Thesoureiro: - Melchior Almeida \\ $2^{\circ}$ “: - Accacio Simões \\ $\mathrm{I}^{\circ}$ Captain: - Freddie Fuller \\ $2^{\circ}$ ": - William Gorst \\ Nada mais havendo que tratar-se, levantou-se a sessão às $2 \frac{1}{2} 2$ horas da tarde. Eu, Carlos \\ Salles Bloch, secretário da assembleia e primeiro secretário do Jundiahy; digo 'Paulista \\ Foot Ball Club', que reescrevi e assigno. \\ Jundiahy, I7 de Maio de I909 \\ Carlos Salles Bloch, \\ Transladada do original, em I ${ }^{\circ}$ de Junho de I909 (Dacta termo de abertura)5.
}

Salienta-se que na ata de fundação do Paulista F.C., transcrita acima, o próprio secretário se confunde ao chamar a nova organização de Jundiahy, evidenciando a continuidade entre a nova agremiação esportiva e a anterior. A partir da fundação, o Paulista F.C. passou a reunir cada vez mais sócios, que se juntavam para a prática recreativa do futebol. Havia inclusive duas divisões de equipes. Uma era a divisão em primeiro e segundo quadros, que seriam os responsáveis por representar o clube em partidas com outras agremiações. A outra era a divisão interna de times formados por membros do próprio clube, que realizavam partidas entre si. Assim, as divisões se distinguiam por cores (time vermelho, time branco, time preto etc.), que eram representadas por seus respectivos capitães. Desse modo, mesmo quem não estivesse no primeiro quadro teria espaço para a prática do futebol, ainda mais considerando-se que o esporte bretão naquele contexto ainda era praticado de forma amadora e que o profissionalismo só viria a ser adotado pelo Paulista F.C. na virada dos anos I940 para a década de I950 (GOTTARDO, 20I8, p. I5-I6).

Ao reunir a identidade dos sócios do Paulista F.C. nos anos compreendidos entre I909 e I920 e cruzar com as informações do banco de dados "Ferrovia, cidade e trabalhadores, a conquista do Oeste (I850-I920)", identificamos 44 indivíduos comuns

5 Ata de Fundação do Paulista Foot Ball Club, I7 de maio de I909. Nas transcrições, foram mantidas a grafia e a pontuação originais dos documentos. 
que constam nas duas fontes (ver Figura I). O número se explica pela alta incidência de homônimos e pela dificuldade de confirmarmos se os mesmos nomes se referem necessariamente às mesmas pessoas. Dos 44 indivíduos selecionados, nos foi possível identificar a nacionalidade de 37 deles, sendo 3I brasileiros. Os seis estrangeiros vinham da Inglaterra (Jayme Chittenden), da Itália (Rosario Bruno e Antonio Grassi), de Portugal (Melchior Almeida), da Escócia (Adão Gray) e da Espanha (Antonio Marques Mora). Mesmo entre os trabalhadores brasileiros, é possível reconhecer alguns de ascendência estrangeira, como é o caso dos irmãos Normanton, filhos do inglês John Normanton, que jogou pelo Jundiahy F.C. na partida inaugural contra a União da Lapa (RIBEIRO; BONI, 20I3, p. 83).

O exame da documentação nos indica que 27 indivíduos tinham registradas sua cor de pele, sendo todos eles definidos como brancos, o que está em acordo com a dificuldade de inserção dos negros nos espaços futebolísticos, conforme apontado por Santos (20I0). Além disso, a presença de estrangeiros era comum em clubes de futebol e nas empresas ferroviárias durante as primeiras décadas do século XX. Segundo Ferreira (2004), a convivência entre imigrantes e brasileiros era muitas vezes conturbada nos espaços do trabalho ferroviário. Em especial, as tensões entre brancos estrangeiros e negros brasileiros criavam divisões no ambiente profissional, o que frequentemente gerava obstáculos para a ascensão dos negros dentro das empresas. No caso do Paulista F.C., os prontuários funcionais dos ferroviários revelam que a presença de estrangeiros não implicava em maior tensionamento de eventuais conflitos raciais, já que todos os integrantes do clube que tiveram a cor da pele especificada foram registrados como brancos. O levantamento realizado por Lanna (20I6, p. 524) também reforça esse traço étnico entre os funcionários da Companhia Paulista ao revelar o baixo número de negros contratados pela empresa entre I870 e I9I9 em comparação ao número de brancos.

O material empírico nos revela também a idade de admissão na Companhia Paulista de 36 dos 44 indivíduos arrolados, conforme pode ser consultado na Figura I - 30 deles ingressaram com menos de 20 anos de idade, sendo os mais novos com I2 anos; os outros seis tinham entre 20 e 23 anos, o que também indica que se tratava de jovens. A idade de admissão no grupo escolhido fica em pouco mais de I6 anos em média. O mais comum entre esses jovens era iniciarem as atividades na Companhia Paulista como aprendizes ou praticantes. Dos I8 indivíduos selecionados que ingressaram na empresa com I5 anos ou menos, apenas um (Amadeu Gianazzi) não começou por meio de um desses cargos de iniciante. O restante ocupou funções de aprendiz - ajustadores, fundidores, torneiros ou carpinteiros - ou praticante nas atividades de escriturário, telegrafista, entre outras.

O salário inicial da maioria dos trabalhadores era consideravelmente baixo devido, em geral, à pouca idade, variando entre $\$ 500$ e I\$800 ao dia. Para efeito de comparação, o vencimento de um fundidor à época era de $8 \$ 000$ ao dia, enquanto rebitadores e foguistas ganhavam cerca de 7 \$00o por jornada diária. Entretanto, além dos dados relativos à idade, ao cargo e ao salário no momento do ingresso na Companhia daqueles que se tornaram membros do Paulista F.C., é importante observarmos como eles deixaram de trabalhar na ferrovia. Da nossa amostra de 44 ferroviários, impressionantes 39 se aposentaram na empresa, sendo cinco deles 
com aposentadoria especial. Outros três faleceram enquanto eram empregados da estrada (Waldemar de Godoy, Benedicto Santos e Wenceslau Zmylowski), sendo um outro exonerado (Benedicto Pompeu) ${ }^{6}$ e um último demitido (Melchior Almeida)7.

A partir de outro ângulo de análise, apenas dois, da totalidade dos nomes arrolados, não foram funcionários da Companhia Paulista até o fim de suas vidas profissionais. Isso reflete a ideia de que era comum aos trabalhadores construírem suas carreiras dentro de uma única empresa, o que evidentemente contribuía para a formação e o fortalecimento da identidade ferroviária e da noção de "família ferroviária”. Afinal, o indivíduo era admitido muito jovem e passava a vida inteira trabalhando com as mesmas pessoas, no mesmo ambiente, buscando aos poucos alçar-se a postos de trabalho mais qualificados dentro da hierarquia ocupacional da estrada de ferro. Esse aspecto pode ainda ser reforçado quando se observa que a média de permanência como funcionário da Paulista, entre aqueles que se aposentaram na Companhia, é de 36 anos.

De todos os funcionários que encerraram suas carreiras na empresa, encontramos I2 que eram membros do Paulista de Jundiaí e que permaneceram mais de 40 anos trabalhando na Companhia Paulista, a maioria dos quais ingressou na década de I900 e saiu apenas nos anos I940. Entre esses I2, a média de tempo de dedicação ao trabalho na ferrovia é de cerca de 43 anos. O sócio do clube futebolístico com maior tempo de atuação na Companhia é o sr. Nicomedes Correa, que foi empregado por 50 $a_{n o s}^{8}$ e sobre o qual falaremos mais adiante.

Quanto ao cargo no momento de saída da empresa, esse variava de acordo com a trajetória traçada por cada trabalhador. O sr. Augusto Maia, por exemplo, entrou em I9I3, aos I5 anos de idade, como aprendiz de carpinteiro, ganhando um ordenado de $\$ 500$ ao dia. Quando se aposentou, em I949, ele atuava como modelador e recebia um salário de \$900 por hora9. Já o sr. Eugênio Zichel, que também começou a trabalhar na Paulista aos I5 anos de idade, iniciou em I9II como aprendiz de torneiro e permaneceu na empresa por 38 anos. Quando se aposentou, ocupava a função de $I^{\circ}$ oficial e ganhava $2 \$ 500$ por hora de trabalho ${ }^{\mathrm{TO}}$.

Há, contudo, algumas dificuldades de análise em se comparar os salários dos trabalhadores no momento de suas aposentadorias. Em primeiro lugar, nem todos se aposentaram sob o regime da mesma moeda, dado que em 1942 o mil-réis foi substituído pelo cruzeiro. Além disso, nem todas as remunerações estão expressas na

6 Cp. 75.3-2, prontuário II7, ficha I566. Arquivo Geral da Fepasa, Banco de Dados Ferrovia, Cidade e Trabalhadores, a conquista do Oeste (I850-I920).

7 Cp. 75.4-34, prontuário IIIo, ficha 2I2. Arquivo Geral da Fepasa, Banco de Dados Ferrovia, Cidade e Trabalhadores, a conquista do Oeste (I850-I920).

8 Cp. 75.4-72, prontuário I598 ficha 3I3. Arquivo Geral da Fepasa, Banco de Dados Ferrovia, Cidade e Trabalhadores, a conquista do Oeste (I850-I920).

9 Cp. 75.4-5I, prontuário I348, ficha 273. Arquivo Geral da Fepasa, Banco de Dados Ferrovia, Cidade e Trabalhadores, a conquista do Oeste (I850-I920).

Io Cp. 75.4-3I, prontuário I082, ficha I460. Arquivo Geral da Fepasa, Banco de Dados Ferrovia, Cidade e Trabalhadores, a conquista do Oeste (I850-I920). 
documentação primária sob a mesma unidade de tempo, ou seja, há funcionários cujo último salário está registrado por hora, enquanto outros têm o valor lançado por dia ou por mês. Isso, além do fato de se tratar de valores nominais, limita a comparação entre os vencimentos dos indivíduos analisados.

Retomando a questão da longevidade dos sócios da agremiação esportiva dentro da empresa ferroviária, observamos que isso só era possível devido ao caráter amador da atividade futebolística do Paulista F.C. à época, o que permitia a conciliação entre o trabalho na ferrovia e a participação eventual como jogador do clube. Os gramados e os trilhos não eram excludentes, mas complementares na vida do trabalhador jundiaiense.

Outro aspecto que salta aos olhos refere-se à hereditariedade da categoria ferroviária entre os sócios do Paulista de Jundiaí. Ao investigar os membros do Clube, cujas fichas profissionais foram identificadas no Banco de Dados Ferrovia, Cidade e Trabalhadores, a conquista do Oeste (I850-I920), é possível encontrarmos casos em que o filho seguiu a mesma trajetória do pai ao se tornar ferroviário. O percurso profissional do sr. Conrado Föelkel, por exemplo, é emblemático nesse sentido. Os filhos Arnaldo ${ }^{\text {II }}$ e Conrado Júnior ${ }^{\mathrm{T2}}$ entraram na Companhia Paulista respectivamente como aprendiz de ajustador, em I9I3, e praticante de escriturário, em I9I5, ambos com I4 anos. Em seguida, passaram cerca de 36 anos na empresa, antes de se aposentarem - Arnaldo em setembro de I949 e Conrado Júnior em dezembro de I950. O pai, Conrado Föelkel, havia sido eleito por unanimidade pela assembleia geral do Paulista F.C. como sócio honorário do Clube.

Além de Föelkel, outro sócio honorário do Paulista viu seus filhos fazerem carreira na estrada de ferro. Trata-se do inglês João (John) Normanton, que atuou como goleiro do Jundiahy F.C. naquela primeira partida da equipe contra a Associação Atlética União da Lapa (RIBEIRO; BONI, 20I3, p. 83). Seu filho Sydney John Normanton ${ }^{13}$ ingressou na Companhia Paulista em I907, aos I5 anos, como aprendiz de ajustador. Ao longo da carreira, foi ferreiro, $\mathrm{I}^{\circ}$ oficial e mestre ferreiro. Sua aposentadoria se deu após 42 anos de serviço. Já João Normanton Júnior ${ }^{14}$ iniciou em I9I6 como praticante de escriturário. Em mais de 33 anos de carreira, ele passou por Jundiaí e Campinas, atuando primeiramente como escriturário, chegando até à chefia da secretaria. Nos prontuários da Companhia Paulista, há ainda o registro de um terceiro Normanton, chamado Benjamin, que, segundo Ribeiro e Boni (2013, p. 83), também era filho de John Normanton. Benjamin entrou na ferrovia aos I 4 anos

II Cp. 75.4-56, prontuário I403, ficha 338. Arquivo Geral da Fepasa, Banco de Dados Ferrovia, Cidade e Trabalhadores, a conquista do Oeste (I850-I920).

I2 Cp. 75.4-I40, prontuário 2597, ficha 745. Arquivo Geral da Fepasa, Banco de Dados Ferrovia, Cidade e Trabalhadores, a conquista do Oeste (I850-I920).

I3 Cp. 75.4-I44, prontuário 2648, ficha 766. Arquivo Geral da Fepasa, Banco de Dados Ferrovia, Cidade e Trabalhadores, a conquista do Oeste (I850-I920).

I4 Cp. 75.4-44, prontuário I263, ficha I24. Arquivo Geral da Fepasa, Banco de Dados Ferrovia, Cidade e Trabalhadores, a conquista do Oeste (I850-I920). 
como aprendiz de ajustador e permaneceu na empresa por 38 anos, se aposentando como chefe da turma de ajustadores ${ }^{15}$.

Além dos Normanton, há ainda o exemplo dos Tordello. O sr. Emílio Tordello' sócio do Paulista F.C., fez carreira na Companhia Paulista, onde trabalhou por 36 anos, e ainda viu seus dois filhos atuarem na mesma empresa. Em I934, aliás, Emílio enviou uma carta ao sr. José de Oliveira Brochado, então chefe da Contadoria e Estatística da Companhia Paulista (LANNA, 20I6, p. 530-53I). Nesse documento, ele solicita a admissão do filho João na ferrovia, o que, de acordo com a correspondência, era "um desejo do pai, o qual seja, o de encaminhar seu filho à senda sublime do trabalho e do devir"

Um último caso que merece nossa menção é o do sr. Henrique West, cujos filhos Henrique West Filho e Francisco Alfredo West também trabalharam na Companhia Paulista. Dos dois, apenas a ficha de Francisco Alfredo consta no Banco de Dados Ferrovia, Cidade e Trabalhadores, a conquista do Oeste (I850-I920), revelando que sua trajetória profissional teve início em I902, atuando como aprendiz de aplainador, e terminou em I932 ao se aposentar com cargo não especificado no prontuário ${ }^{\mathrm{I8}}$.

Os exemplos anteriores evidenciam como o Paulista F.C. de Jundiaí era formado por trabalhadores que se encaixam no perfil por nós identificado da "hereditariedade ferroviária”, conforme descrito na introdução deste estudo. Nota-se também como muitos desses "herdeiros" não só iniciaram a carreira na estrada de ferro como seguiram também o modelo do chamado carreirismo ao permanecerem na Companhia Paulista durante toda a vida profissional.

Outra observação a ser feita sobre os 44 indivíduos identificados é que 5 deles tiveram passagens registradas por outras empresas ferroviárias do estado de São Paulo, além da Companhia Paulista. O sr. Carlos Jorge Marques, por exemplo, passou o período de I890 a I894 trabalhando na Companhia Mogiana de Estradas de Ferro, tendo atuado em Campinas, Valinhos e Cordeiro (atual município de Cordeirópolis) como telegrafista, escriturário e chefe de estação, respectivamente ${ }^{\text {I. }}$. Além dele, o sr.

I5 Cp. 75.4-I69, prontuário 2948, ficha 950. Arquivo Geral da Fepasa, Banco de Dados Ferrovia, Cidade e Trabalhadores, a conquista do Oeste (I850-1920).

I6 Cp. 75.4-79, prontuário I650, ficha 220. Arquivo Geral da Fepasa, Banco de Dados Ferrovia, Cidade e Trabalhadores, a conquista do Oeste (I850-I920).

I7 O trecho da carta foi extraído do campo “observações”, relativo ao prontuário do Sr. Emílio Tordello: Cp. 75.4-79, prontuário I650, ficha 220. Arquivo Geral da Fepasa, Banco de Dados Ferrovia, Cidade e Trabalhadores, a conquista do Oeste (I850-I920).

I8 Cp. 75.4-I9I, prontuário 3290, ficha II52. Arquivo Geral da Fepasa, Banco de Dados Ferrovia, Cidade e Trabalhadores, a conquista do Oeste (I850-I920).

I9 Cp. 75.4-I98, prontuário 3390, ficha II8I. Arquivo Geral da Fepasa, Banco de Dados Ferrovia, Cidade e Trabalhadores, a conquista do Oeste (I850-I920). 
Melchior Almeida também passou cinco anos (de I896 a I90I) na Mogiana ${ }^{20}$, assim como o sr. José Mantilla, que ficou dois anos nessa mesma empresa (de I896 a I898) ${ }^{21}$.

Já o sr. Accacio Simões ${ }^{22}$, um dos fundadores do Paulista F.C., começou na Companhia Estrada de Ferro Rio Claro, além de ter passado pela Companhia Bragantina antes de ingressar na Paulista em I898. Outro com trajetória semelhante foi o sr. Adão Gray ${ }^{23}$, que foi funcionário da Companhia Estrada de Ferro Sorocabana, entre I903 e I904, e que também teve uma passagem por Campinas e Rio Claro antes de se aposentar em I93I. O escocês Gray, aliás, foi presidente em I9I4 de outro clube de futebol originário de uma empresa ferroviária, o Rio Claro F.C. ${ }^{24}$. Nesse mesmo período, ele também esteve à frente do Grêmio Recreativo dos Empregados da Companhia Paulista (MINA, 20I7, p. 88).

A prática de trabalhar em outras ferrovias, ou em outros pontos do estado de São Paulo, também pode ser observada em relação a alguns membros do Paulista F.C. que, no entanto, não transparecem no Banco de Dados Ferrovia, Cidade e Trabalhadores, a conquista do Oeste (I850-I920). É o caso do primeiro presidente do Paulista F.C., o inglês John Lewis Jones, que comandou a agremiação entre I909 e I9I4. Na década de I920, Jones trabalhou em Rio Claro, onde ocupou o cargo de mestre geral das oficinas da Companhia Paulista e integrou a diretoria do Rio Claro F.C. Conforme documentação examinada por Mina (20I7, p. IOo-IOI), o ex-presidente do Paulista F.C. era o responsável, dentro da Companhia Paulista, por autorizar a liberação do passe do trem para a prática do ludopédio tanto para os times que iam a Rio Claro enfrentar a equipe homônima, quanto para a própria esquadra local visitar outra agremiação para uma partida.

20 Cp.75.4, prontuário 757, ficha I52I. Arquivo Geral da Fepasa, Banco de Dados Ferrovia, Cidade e Trabalhadores, a conquista do Oeste (I850-I920).

2I Cp. 75-4-I56, prontuário 2793, ficha 855. Arquivo Geral da Fepasa, Banco de Dados Ferrovia, Cidade e Trabalhadores, a conquista do Oeste (I850-I920).

22 Cp. 75.4-I37, prontuário 2593, ficha 7I6. Arquivo Geral da Fepasa, Banco de Dados Ferrovia, Cidade e Trabalhadores, a conquista do Oeste (I850-I920).

23 Cp. 75.4-I38, prontuário 2572, ficha 687. Arquivo Geral da Fepasa, Banco de Dados Ferrovia, Cidade e Trabalhadores, a conquista do Oeste (I850-I920).

24 A lista de presidentes ao longo da história do Rio Claro Futebol Clube pode ser consultada no site do próprio clube. Sobre a história da Companhia E.F. Rio Claro, que em I892 foi adquirida pela Companhia Paulista, ver: Grandi (2007). 


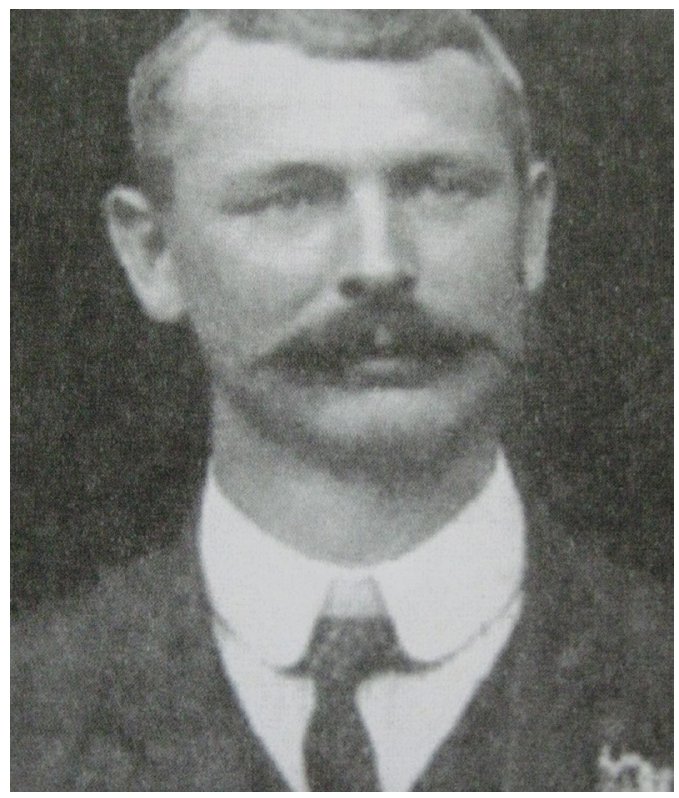

Figura 3 - John Lewis Jones, o primeiro presidente do Paulista F.C. Fonte: Acervo de Imagens do Centro de Memória de Jundiaí

Vale a pena citarmos também o caso do sr. Nicomedes Correa, que foi um dos fundadores do Grêmio Recreativo dos Empregados da Companhia Paulista em I90o. Nesse ano, ele havia entrado na empresa como aprendiz de fundidor em Jundiaí. Após diversos anos atuando como carpinteiro e integrando o quadro social do Paulista F.C., Correa foi deslocado em I929 para Rio Claro, onde também se envolveu com o Rio Claro F.C. ao presidi-lo no ano de I930. Em I932, foi mais uma vez transferido para outro município atendido pela ferrovia, Marília, onde trabalhou na seção de fundição. No final da década, mais uma transferência, agora para São Carlos, cidade em que ocupou o cargo de inspetor de carros e vagões, mesma função que desempenhou na década de I940 em Campinas. Aposentou-se em I950, após 50 anos de serviços prestados à Companhia Paulista ${ }^{25}$.

Um último caso de relevo a ser apresentado é o do escocês Thomas Archibald Scott, que se envolveu com a Associação Atlética Ponte Preta, de Campinas. De acordo com Lucato (2002, p. 87-90), o sr. Scott, junto com o filho J. Scott, teria participado da fundação da equipe campineira em I900, sendo um profundo conhecedor das regras do esporte bretão. Dois anos depois se mudou para Jundiaí em decorrência do surto de febre amarela que assolou Campinas, ajudando a implantar o futebol em solo jundiaiense. Scott participou da partida a qual já mencionamos entre o Jundiahy e a União da Lapa, em I903, e ocupou o cargo de diretor fiscal do Paulista F.C. no ano de fundação do Clube. Faleceu em I9I3, em Jundiaí, e ao longo de todo esse período mencionado foi funcionário da Companhia Paulista.

25 Cp. 75.4-72, prontuário I598, ficha 3I3. Arquivo Geral da Fepasa, Banco de Dados Ferrovia, Cidade e Trabalhadores, a conquista do Oeste (I850-I920). 
As trajetórias dos indivíduos citados servem para ilustrar como o futebol acompanhou a vida de profissionais ligados às ferrovias. Quando transferidos e realocados, os trabalhadores da Companhia Paulista traziam às novas cidades não só as suas capacidades de ofício, como também as suas formas de entretenimento e lazer - entre elas, a prática do futebol. As redes de organização dos trabalhadores ferroviários, cujas ligações eram inicialmente profissionais, se estendiam para além dos horários de serviço e ajudavam na concepção da "família ferroviária". Nesse cenário, o arranjo coletivo do lazer para a prática esportiva favoreceu a disseminação do futebol ao longo das regiões do estado alcançadas pelas linhas férreas.

\section{UM OLHO NO TREM, OUTRO NA BOLA: A IMBRICADA RELAÇÃO DO Clube com a Companhia}

Mesmo vestindo as cores e assumindo o nome da empresa, é importante observarmos que o Paulista F.C. não pertencia à ferrovia, mas aos ferroviários. Porém, isso não quer dizer que a Companhia não tivesse participado direta ou indiretamente no Clube, exercendo, portanto, o papel de pater familis da "família ferroviária”. Pelo lado da empresa, a organização dos trabalhadores favorecia a "moral patronal" ao reforçar a ideia de "família ferroviária" e salientar os valores cultivados no espaço profissional (INOUE; GRANDI, 202I). Mais do que isso, o próprio futebol fornecia uma base disciplinadora compatível com os princípios difundidos pela direção da estrada de ferro.

Pinto (2007, p. 44) esclarece que o ludopédio - acessível para qualquer coletivo em posse de um objeto minimamente próximo a uma esfera que pode ser chutada - trazia consigo o significado do ensinamento por meio de regras sociais no espaço do lazer. Assim, a disciplina, enquanto componente básico do jogo (através das delimitações comportamentais via regras, advertências e punições), se encaixava na configuração industrial do trabalho, que tinha por base os modelos europeus e estadunidenses, os quais as ferrovias brasileiras procuravam reproduzir.

Zambello (2005, p. 26I) salienta que o compartilhamento dos espaços de lazer e do tempo livre pelos trabalhadores gerava um quadro de vigilância disciplinadora exercida pelos próprios operários. O pesquisador se refere, em especial, às vilas operárias erguidas próximas aos locais de trabalho, prática também exercida pela Companhia Paulista, além de outras empresas ferroviárias de São Paulo.

Através do Banco de Dados Ferrovia, Cidade e Trabalhadores, a conquista do Oeste (I850-I920), nos foi possível identificar apenas seis sócios do Paulista cuja situação de morada havia sido registrada. Dessa meia dúzia, cinco viviam em casas fornecidas pela empresa: é o caso do sr. Manoel Penna, do sr. Jayme Chittenden, do sr. Antonio Marques Mora, do sr. Amadeu Gianazzi e do sr. Attilio Bragantini. Apenas o sr. Ignacio Duarte é listado como proprietário da respectiva casa.

A extensão do domínio e da vigilância da empresa sobre o espaço privado dos trabalhadores se encaixa no que se pode chamar de "lazer autorizado". Inoue e Grandi (202I) abordam a questão, destacando que a presença da firma no horário de descanso visava estimular o chamado bom comportamento e a disciplina, em oposição à vagabundagem, à vadiagem e ao alcoolismo. 
Dentro do cenário descrito, é evidente que a Companhia Paulista exercia uma expressiva influência sobre o ambiente de lazer desportivo dos seus funcionários, mais especificamente sobre o Paulista F.C. Para além da disponibilização dos espaços e dos eventuais empréstimos de materiais, a relação entre as duas partes se mostrava profundamente enraizada. Diversos ofícios encontrados no CMJ atestam que as direções do clube e da ferrovia se comunicavam com certa frequência, mas nunca de forma totalmente institucionalizada: dirigentes e representantes do clube costumavam entrar em contato com os diretores da empresa de modo geralmente pessoal e intimista.

Era comum, por exemplo, membros do Clube solicitarem favores a funcionários do alto escalão da Companhia. Entre esses atos, estavam os já referidos pedidos de transporte gratuito para as equipes de futebol, seja para o próprio time local ou para adversários visitantes. A prática aparece neste ofício, enviado em maio de I9I5 ao sr. Alfredo Williams, chefe de Locomoção da Companhia Paulista em Jundiaí:

Illm $^{\circ}$ Sr. Alfredo Williams

D.D. Chefe de Locomoção

Desejando os rapazes do PAULISTA FOOT BALL CLUB de que sou humilde presidente jogar amanhã, em Campinas um match de foot ball com um dos clubs daquella cidade, venho por esta pedir à V.S. a concessão de um passe para II jogadores, dos quaes 5 os Srs. Jorge Normanton, - Americo Bertoline, - William Gorst, - José Müller e Antonio Giovanne são empregados nas Officinas, 3 da Locomoção os Srs. Dino Siqueira, - João Siqueira e Octavio de Oliveira e 2 da Contadoria os Srs. Nestor Simões e Guilherme Aranha e finalmente I que não é empregado da Cia. Paulista.

De antemão agradecido, subscrevo me

De V.S.

$\mathrm{Att}^{\circ}$ Venr e $\mathrm{Cr}^{\circ}$

Tibúrcio Siqueira

Presidente ${ }^{26}$

Uma particularidade é que esse documento, ao contrário de outros que são assinados pelo então primeiro secretário, o sr. Carlos Cordts, traz a assinatura do presidente da agremiação, Tibúrcio Siqueira. Isso se explica pelo fato de se tratar de um contato direto com um quadro da chefia da Companhia Paulista, e não com um "mero" funcionário da ferrovia, o que demandava um esforço mais formal e oficial, expressando a devida atenção e respeito a um superior hierárquico.

Além de constatar que a maior parte dos jogadores que pretendiam ir a Campinas para a partida de futebol atuava nas oficinas da Paulista em Jundiaí, o ofício ainda nos permite depreender que a justificativa do pedido seria o fato dos atletas serem quase todos funcionários da ferrovia. A carta traz um raciocínio segundo o qual os

26 Livro de Ofícios do Paulista Foot Ball Club - 5 jan. I9I5 a I3 fev. I9I9, p. II4. Ofício enviado entre os dias 20 e 29 de maio de I9I5 ao sr. Alfredo Williams. 
serviços prestados pelos empregados à empresa podem ser equiparados ao serviço que a empresa pode oferecer ao transportar seus funcionários.

A ideia de retribuição aparece com mais clareza no ofício enviado em janeiro de I9I7 ao chefe do tráfego da Companhia Paulista. No documento, a diretoria do clube pede ao superior doações para a construção do estádio da Vila Leme, que seria inaugurado em junho de I9I8:

\section{II de Janeiro de I9I7}

EXMO Dr. Gabriel Penteado

D.D. Chefe do Tráfego da Companhia Paulista

\section{CAMPINAS}

A Directoria do 'Paulista Foot Ball Club' desta cidade, estando empenhada na construção de uma ordem de archibancada no seu ground, tem para o conseguimento desse desideratum appellado para a generosidade de pessoas bondosas, dentre as quaes se destacam os dignos Administradores da Companhia Paulista.

Assim é que o Exm. Sr. Dr. Monlevade, seu presidente honorário e os Exms. Snrs. Dr. Alberto Moreira e Alfredo Williams a teem auxiliado, o primeiro fazendo-lhe doação de madeira e isentando-a de fretes; o segundo doando-lhe diversos dormentes e o último mandando desdobrar nas officinas vários toros de peroba.

Escudada na boa vontade demonstrada por esses distinctos cavalheiros e convicta de que da generosidade de V. Exia é dado esperar a mesma boa vontade, vem a Directoria pedir lhe seja feita a cessão por preço o mínimo possível e pede o obséquio de informar qual será, de io encerados velhos de que precisa para a coberta de ditas archibancadas. Aguarda o favor de sua resposta que de antemão muitíssimo agradece.

Pela Directoria

Tiburcio Siqueira, presidente

Carlos Cordts - Secretário ${ }^{27}$.

A carta evidencia a expectativa dos membros do Clube para com os diretores da ferrovia, esperando a demonstração de boa vontade através da doação de recursos. Não se tratava, todavia, de uma simples contribuição; o tom que mistura cobrança, cordialidade e bajulação expõe as nuances da relação entre o Paulista F.C. e a Companhia Paulista. Se, por um lado, o respeito profissional se expressava pela formalidade da mensagem, por outro, o tom de bajulação parecia, por vezes, sugerir que a relação existente entre as diretorias extrapolava a dimensão estrita das relações de trabalho, pois, afinal, tais condutas podem ser compreendidas como sinais de intimidade entre as partes e excessiva proximidade pessoal. A esse respeito, parece haver certa sobreposição entre as noções de contribuição e retribuição, pois, ao que tudo indica, tal visão era compartilhada pelos diretores da ferrovia, que, de fato, costumavam atender aos pedidos dos ferroviários boleiros.

Um último ponto a ser explorado sobre o ofício enviado ao dr. Gabriel Penteado é a menção ao dr. Francisco Monlevade, inspetor-geral da Companhia Paulista entre I906 e I925. Monlevade era conhecido entre os ferroviários por cometer frequentes

27 Livro de Ofícios do Paulista Foot Ball Club - 5 jan. I9I5 a I3 fev. I9I9, p. 375. Ofício enviado no dia II de janeiro de I9I7 ao sr. Gabriel Penteado. 
abusos de autoridade, tendo inclusive sido um dos principais alvos e adversários dos ferroviários que realizaram a grande greve de I906, após a qual foi promovido ao cargo em que permaneceu por quase duas décadas (ZAMBELLO, 2005, p. 82). Conforme apresentado no documento, o dr. Monlevade recebeu o título de presidente honorário do Paulista F.C. Em diversas cartas enviadas pela agremiação ao diretor, é evidente que a relação mantida com o inspetor-geral era particularmente paternal e repleta de bajulação e de demonstrações de reverência.

O ofício a seguir, enviado por ocasião da reforma do campo da Vila Leme, e transcrito do Livro de Ofícios do Paulista Foot Ball Club, que contém documentos de janeiro de I92I a abril de I922, ilustra devidamente como tal relação se configurava:

Jundiahy, 5 de abril de 1922.

Exmo Snr. Dr. Francisco Paes Leme de Monlevade

Digníssimo Inspector Geral da Companhia Paulista,

NESTA,

Tenho a honra de acusar recebimento do officio de D. Exc. communicando haver a digna Directoria da Companhia Paulista concedido gratuitamente o material destinado à melhoria da nossa praça de esportes, cujo pedido a ella fora encaminhado por V. Exc. O Paulista Foot-ball Club agradece de joelhos a concessão de um favor tão relevante sem o qual não lhe seria permittido levar avante os projectados melhoramentos que lhe virão dar uma posição de destaque e de verdadeiro brilho no esporte do interior. A V. Exc. tão solícito em atender a esse pedido, por elle se interessando com a boa vontade que caracterisam todos os actos da maior glória da engenharia brasileira e que por felicidade nossa superintende os destinos desta grande empreza, a nossa gratidão.

Aproveitamos o ensejo para levar ao conhecimento de V. Exc. que após luctas memoráveis, nas quaes sempre triumphamos, pois não perdemos um só jogo, acabamos de conquistar mais uma vez o título de Campeão do Interior do Estado de São Paulo, distincção máxima que o esporte concede ao Club que mais se distingue. E para honra da empreza a que pertencemos e de quem tiramos o nome, essa distinç̧ão coube a nós, como justa recompensa a tantos exforços despendidos.

Respeitosas saudações,

Presidente ${ }^{28}$.

Como é possível notar, o documento traz uma série de elementos que devem ser analisados separadamente, mas que em conjunto sintetizam e simbolizam a relação entre o Paulista F.C. e a diretoria da Companhia Paulista. O primeiro aspecto que captura nossa atenção é a veemência dos elogios ao inspetor-geral da Companhia. Mais do que reconhecimento por atos benevolentes, a carta se preocupa em exaltar exacerbadamente o diretor e a ferrovia, ao mesmo tempo que coloca o Clube - e, consequentemente, os funcionários - em uma posição de submissão. As expressões "maior glória da engenharia brasileira" e "agradece de joelhos" são os exemplos mais emblemáticos do que estamos pontuando.

28 Livro de Ofícios do Paulista Foot Ball Club - I9 jan. I92I a abr. I922, p. III. Ofício enviado no dia 5 de abril de I922 ao dr. Francisco Paes Leme de Monlevade. 
A parte final do ofício trata do sucesso esportivo do Paulista F.C., revelando que o Clube, além de trazer consigo um grande orgulho pela conquista invicta do Campeonato do Interior, estende à empresa tal sentimento. Pela ótica dos boleiros, a honra pelo título pertence também à ferrovia, a qual deve se sentir orgulhosa dos seus funcionários.

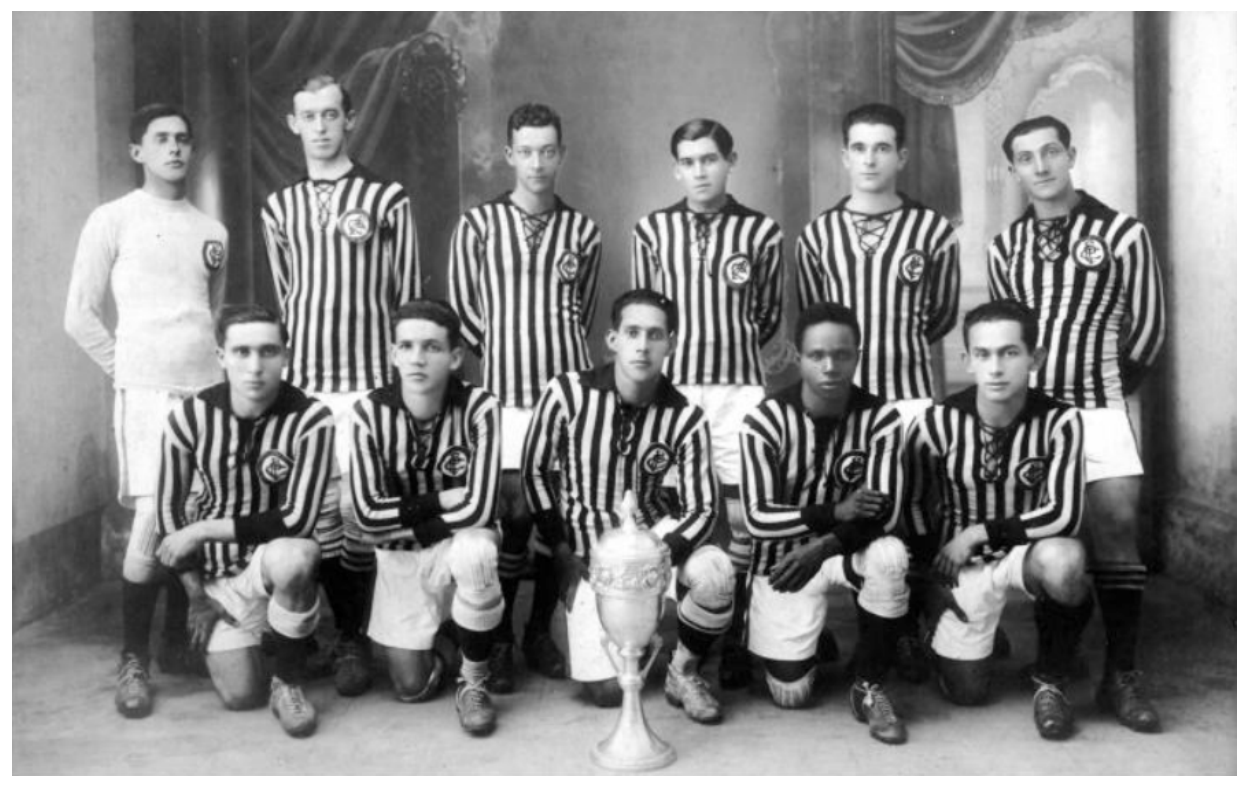

Figura 4-Equipe do Paulista F.C. vencedora do Campeonato do Interior de I92I. Fonte: Paulista Futebol Clube

O ofício ilustra, por si só, os desdobramentos das relações paternalistas que vigoravam na empresa. A solicitação (e subsequente aceite) de uma prestação de favor aliada ao tom personalista e bajulador - cujo alcance extrapola a relação estritamente profissional - e à manifestação de um orgulho visto como uma via de mão dupla denotam o caráter paternalista que permeava a relação entre os integrantes do Paulista F.C. e a chefia da Companhia Paulista. Ademais, o tratamento dado a Francisco Monlevade como benfeitor e símbolo máximo da figura do pater familis é um sintoma da existência de vínculos que se davam para além do ambiente de trabalho ao invadir o tempo livre e as atividades de lazer dos ferroviários.

\section{CONSIDERAÇõES FINAIS}

O presente artigo buscou retratar, por meio de fontes primárias diversas, a primeira geração de jogadores do Paulista F.C., traçando o perfil profissional dos ferroviários e o papel exercido pela Companhia Paulista de Estradas de Ferro na organização da agremiação esportiva e no seu fomento. A pesquisa indica as duas vias da relação 
entre as partes mencionadas, explicitando a compatibilidade desse percurso histórico com as noções de "família ferroviária" e paternalismo, amplamente exploradas pela historiografia especializada no tema das relações de trabalho nas ferrovias paulistas.

É evidente que o alcance deste estudo não deve ser superdimensionado. Afinal, trata-se de um estudo voltado a um único caso, tendo como espectro temporal o período de pouco mais de uma década. Não se pode, portanto, inferir que as relações entre empresas ferroviárias e clubes de futebol tenham assumido a mesma configuração por todo o estado de São Paulo e ainda mais por todo o Brasil. Em hipótese alguma, defendemos esse tipo de argumento de viés generalista. Não obstante, o caso do Paulista F.C. pode ser visto como sintomático - e não necessariamente representativo - de um arranjo trabalhista que implica em uma dinâmica específica de relações sociais, cujo legado bem como o caráter de path dependence $e^{29}$ podem ser verificados até hoje em alguns campos e equipes de futebol pelo Brasil.

\section{SOBRE OS AUTORES}

GUILHERME GRANDI é professor da Faculdade de Economia, Administração e Contabilidade da Universidade de São Paulo (FEA/USP). ggrandi@usp.br ttps://orcid.org/0000-0002-6040-0650

MARCELO ROUBICEK é economista formado pela Faculdade de Economia, Administração e Contabilidade da Universidade de São Paulo (FEA/ USP) e jornalista do Nexo Jornal. marcelo.roubicek@gmail.com https://orcid.org/0000-0002-I839-7574

\section{REFERÊNCIAS}

ALMEIDA, Marco Antonio Bettine de; GUTIERREZ, Gustavo Luis; FERREIRA, Ricardo Pellison. Futebol e ferrovia: a história de um trem da industrialização que parte para o noroeste paulista. Revista Brasileira de Educação Física e Esporte, v. 24, n. 2, 2010, p. 249-258.

29 A dependência da trajetória (path dependence) é um conceito frequentemente utilizado pelos autores vinculados à Nova Economia Institucional, que corresponde à influência do passado no presente. De acordo com North (2005, p. 52): "Path dependence is not 'inertia', rather it is the constraints on the choice set in the present that are derived from historical experiences of the past". 
BUCHMANN, Ernani. Quando o futebol andava de trem: memória dos times ferroviários do Brasil. 2. ed. Curitiba: Editora Sesquicentenário, 2004.

COSTA, Wilma Peres. Ferrovia e trabalho assalariado em São Paulo. I7o f. Dissertação (Mestrado em Sociologia). Instituto de Filosofia e Ciências Humanas, Universidade Estadual de Campinas, I976.

FERREIRA, Lania Stefanoni. Racismo na "família ferroviária": brancos e negros na Companhia Paulista em São Carlos. II3 f. Dissertação (Mestrado em Ciências Sociais). Centro de Educação e Ciências Humanas, Universidade Federal de São Carlos, 2004.

GOTTARDO, Ivan Henrique. I968: o ano que o galo cantou. Campinas: Pontes Editores, 2018.

GRANDI, Guilherme. Café e expansão ferroviária: a Companhia E.F. Rio Claro (I880-I903). São Paulo: Annablume, 2007.

INOUE, Luciana; GRANDI, Guilherme. A reinvenção do paternalismo: a Companhia Paulista de Estradas de Ferro entre as décadas de I920 e I940. América Latina en la Historia Económica, v. 28, n. I, 202I, p. I-23.

LANNA, Ana Lucia Duarte. Ferrovia, cidade e trabalhadores. A conquista do Oeste (I850-I920). [S.l: s.n.], 2000.

LANNA, Ana Lucia Duarte. Trabalhadores das ferrovias: a Companhia Paulista de Estrada de Ferro, São Paulo, 1870-I920. Varia Historia, v. 32, n. 59, 2016, p. 505-545.

LUCATO, Claudio. Jundiahy Foot Ball Club ou Paulista F.C. Jundiaí: Literarte, 2002.

MINA, Renan Vidal. A bola e os trilhos: a incorporação do futebol em Rio Claro e o desenvolvimento do Rio Claro Futebol Clube. I79 f. Dissertação (Mestrado em Ciências). Escola de Artes, Ciências e Humanidades, Universidade de São Paulo, 2017.

NORTH, Douglass. Understanding the process of economic change. Princeton, NJ: Princeton University Press, 2005.

O ESTADO de S. Paulo, 23 de junho de I903.

PAULISTA FUTEBOL CLUBE. Galeria. Disponível em: http://paulistafutebol.com.br/o-clube. Acesso em: I5 jun. 2018.

PINTO, Rodrigo. Do passeio público à ferrovia: o futebol proletário em Fortaleza. I56 f. Dissertação (Mestrado em História). Centro de Humanidades. Universidade Federal do Ceará, 2007.

RIBEIRO, Suzana Lopes Salgado; BONI, Marcela. Pontes da memória: história da nossa gente. São Paulo: Prefeitura de Jundiaí/Museu Histórico e Cultural de Jundiaí, 2013.

RIO CLARO FC. Rio Claro Futebol Clube. Galo Azul, o Azulão. Disponível em: https://www.rioclarofc.com. br. Acesso em: I5 jun. 2019.

SANTOS, João Manuel. Revolução vascaína: a profissionalização do futebol e a inserção socioeconômica de negros e portugueses na cidade do Rio de Janeiro (I9I5-I934). 50I f. Tese (Doutorado em História Econômica). Faculdade de Filosofia, Letras e Ciências Humanas, Universidade de São Paulo, 2010.

SEGNINI, Liliane. Ferrovias e ferroviários: uma contribuição para a análise do poder disciplinar na empresa. São Paulo: Cortez, I982.

TEIXEIRA, Déa. A estrutura de poder, o paternalismo e o papel da assessoria técnica gerencial na pequena empresa industrial. Revista de Administração de Empresas, v. 24, n. 2, I984, p. I3-I7.

ZAMBELLO, Mario Henrique. Ferrovia e memória: estudo sobre o trabalho e a categoria dos antigos ferroviários da Vila Industrial de Campinas. 368 f. Dissertação (Mestrado em Sociologia). Faculdade de Filosofia, Letras e Ciências Humanas, Universidade de São Paulo, 2005. 